\title{
Climate group rejects criticism of warnings
}

London. The Intergovernmental Panel on Climate Change (IPCC) has reaffirmed its earlier conclusion that global carbon dioxide emissions must be reduced if the concentration of greenhouse gases in the atmosphere is to stabilize at levels that prevent 'dangerous' climate change.

In doing so, the panel has rejected claims by critics that its conclusions fail to take sufficient account of the implications of continuing uncertainties about mechanisms affecting climate change - for example, the newly acknowledged role of sulphate aerosols in cooling the Earth by reflecting energy from the Sun, or the full impact on the climate of the carbon cycle.

The impact of aerosols, for example, has been used to explain discrepancies between model predictions of warming in the Northern Hemisphere and the lower limits on observed temperature changes. But the report, containing new estimates of the effects of sulphate aerosols, warns that these are highly localized and "cannot be seen as a simple offset to greenhouse gas forcing".

The conclusions are contained in the latest special report from the IPCC's Working Group 1, which were approved last week at a plenary session of the working group held in Maastricht in the Netherlands. The group is responsible for providing scientific information relevant to the Climate Change Convention signed at the Earth Summit in Rio de Janeiro in June 1992.

The IPCC is already drawing up a Second Assessment Report, but this will not be published until November 1995, after the first conference of parties in March in Berlin. At that meeting, countries that have ratified the convention will decide whether it should be strengthened.

At present, the treaty says that signatory countries should aim to restore emissions of carbon dioxide to 1990 levels by the year 2000 , and eventually to stabilize greenhouse gas emissions at levels that prevent "dangerous' climate change.

Since 1992, however, there has been continuing disagreement over the interpretation of the wording of the treaty, which some countries argue does not bind them to stabilize carbon dioxide emissions at 1990 levels after the year 2000. Many industrialized countries feel that even this commitment is not strong enough, but no consensus has yet emerged on what should be done.

At the tenth meeting last month in $\mathrm{Ge}$ neva of the International Negotiating Committee (INC), the body made up of representatives of the signatory nations, negotiators rejected a German proposal under which industrialized nations would cut their emissions by a specified percentage before a set target date.
Germany, which will be the host country next year in Berlin, is still considering tabling such a proposal for discussion. Last week Klaus Töpfer, the German minister of the environment, told the federal parliament that he was contemplating proposing such a protocol with "like-minded countries", which could include Denmark and the Netherlands.

\section{IMAGE UNAVAILABLE FOR COPYRIGHT REASONS}

\section{mission controls are still 'essential'.}

Töpfer says he has not yet decided whether this will be for a new protocol to the treaty. But last week the European Parliament proposed that the European Union take a lead in putting forward a proposal that convention signatories commit themselves to reducing carbon dioxide emission by 20 per cent by 2005 .

The new IPCC report says that, according to various carbon cycle models, stabilizing atmospheric levels of carbon dioxide at less than 750 parts per million by volume (p.p.m.v.), compared to pre-industrial levels of 280 p.p.m.v. and current levels of 360 p.p.m.v., would demand a drop in emissions to below 1990 levels.

In addition, the report provides revised assessments of the global warming potentials (GWP) of other greenhouse gases such as methane - most GWPs have been revised upwards by between 10 and 35 per cent as well as the improved estimate of the cooling effect of sulphate aerosols.

The main function of the Maastricht meeting was to agree on the wording of the

executive and policy-makers summaries, which, together with supporting scientific materials, make up the Special Report. But, the meeting was not immune from pressure from representatives of nongovernmental organizations (NGOs).

Representatives of the fossil-fuel industry, for example, argued for the exclusion from both the executive and policy-makers summaries of calculations of the level of carbon dioxide emissions corresponding to a range of atmospheric stabilization scenarios, saying that the IPCC was not mandated to make such calculations. This suggestion was rejected, with the working group's chairman, Sir John Houghton, the former director of Britain's Meteorological Office, insisting that the IPCC had to be free to explore questions that it feels are relevant in order to maintain its scientific integrity and independence.

Others criticized the implications of the painstaking peer-review process used in producing the latest report. "It's consensus science, it runs the risk of being slightly behind the times," says Patrick J. Michaels, of the University of Virginia, the state climatologist for Virginia. "That's the nature of a consensus document."

Nevertheless - and despite the fact that many of the scientific data in the report have already been published elsewhere - Keith Shine, lecturer in meteorology at the University of Reading and lead author of one of the five chapters, describes the process of compiling the report as being "unquestionably valuable" in bringing all relevant information together in a single document.

The report also boosts the use of computer simulations in assessing the impact on the climate of particular events such as the eruption of Mount Pinatubo in June 1991. The eruption resulted in a large but shortlived increase in aerosols in the stratosphere. This in turn caused an observed surface cooling of about $0.4{ }^{\circ} \mathrm{C}$, while model simulations predicted a global mean cooling of 0.4 to $0.6^{\circ} \mathrm{C}$; Shine describes such results as "encouraging".

Maggie Verrall

\section{Underwater thumps baffle ocean scientists}

San Francisco. Scientists based on the central California coast are trying to identify the origin of a mysterious underwater sound that disturbed surfers and divers for three weeks - and then just as mysteriously disappeared.

The sound, made up of thumps occurring at 10 -second intervals, was compared by one diver to five or six giant bongo drums going off simultaneously. Most experts have concluded that it was of human origin. John Sanders of the Naval Postgraduate School in Monterey says that the school's scientists are confident that the sound was not pro- duced by any naval activities, although they would not say if any navy submarines were in the area. The Scripps Oceanographic Institute denied that the noises were related to their controversial global warming tests, due to start in the area next year.

Khosrow Lashkari of the Monterey Bay Aquarium Research Institute suggests that the sound might have been the mating call of a large fish, such as a grouper. But, unless the sound returns, it is unlikely that the mystery will ever be cleared up.

Joel N. Shurkin 